\title{
Lupus néonatal se manifestant comme une éruption cutanée en forme de papillon
}

\author{
Jérôme Coulombe MD, Julie Barsalou MD MSc
}

Citation : CMAJ 2021 May 31;193:E805. doi : 10.1503/cmaj.202246-f

Voir la version anglaise de l'article ici : www.cmaj.ca/lookup/doi/10.1503/cmaj.202246

$\mathbf{U}$

$\mathrm{n}$ garçon de 3 mois d'origine afro-américaine a été orienté vers la clinique de dermatologie pour une hypopigmentation de la peau perdurant depuis 2 mois et que son pédiatre avait diagnostiquée comme un vitiligo. Avant que l'hypopigmentation se manifeste, les éruptions cutanées étaient de type érythémateux. Le garçon était né à terme par un accouchement vaginal normal après une grossesse sans incident; la circonférence de la tête et la prise de poids le classaient dans le $90^{e}$ centile. Il avait 2 frères ou sœurs et n'avait pas d'antécédents familiaux de maladie auto-immune.

L'hypopigmentation se présentait sur le visage comme une éruption cutanée à la forme distinctive d'un papillon (figure 1) et de multiples taches ovales étaient dispersées sur l'abdomen du patient (annexe 1, accessible en anglais au www.cmaj.ca/ lookup/doi/10.1503/cmaj.202246/tab-related-content). Aucun symptôme de dermatite atopique ou de parakératose

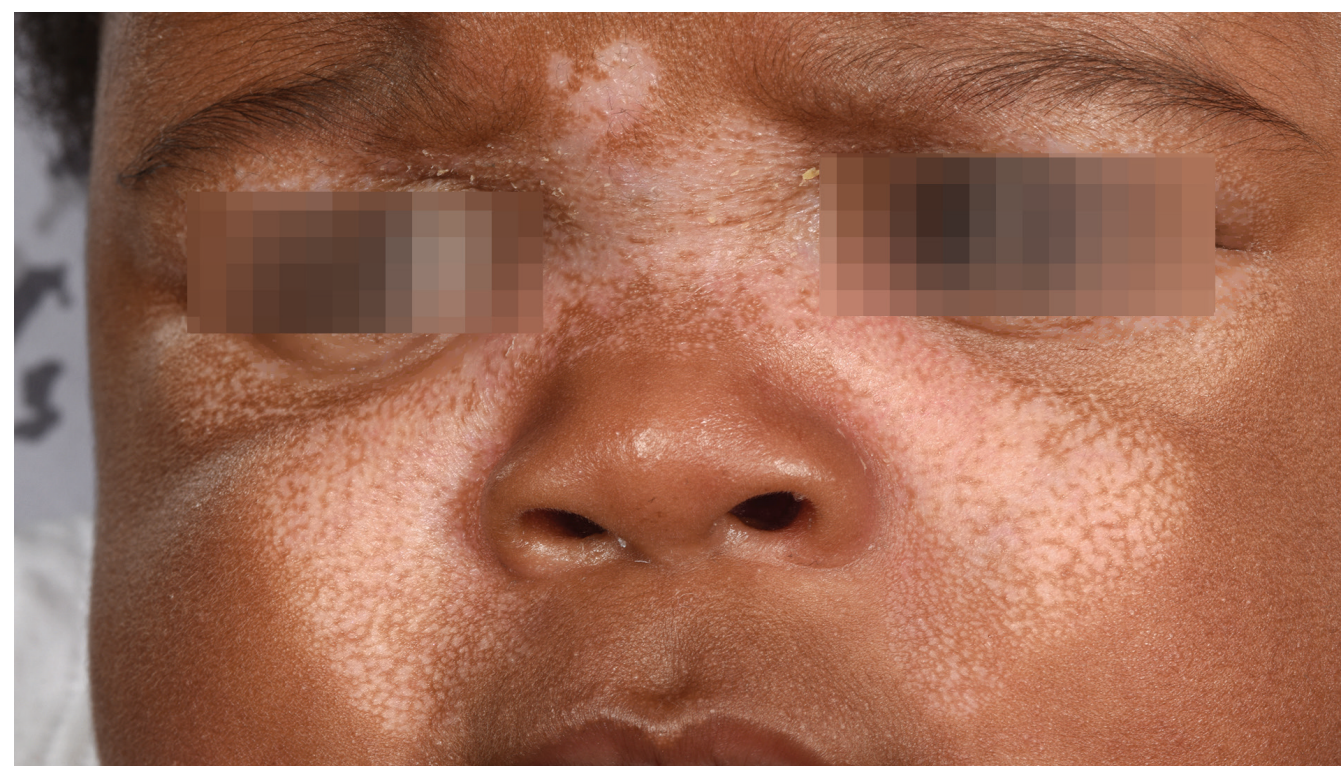

Figure 1 : Hypopigmentation distinctive en forme de papillon sur le visage d'un garçon de 3 mois atteint de lupus érythémateux néonatal. séborrhéique n'était visible. En raison de l'éruption cutanée caractéristique, nous avons soupçonné un lupus érythémateux néonatal, ce qui a orienté notre enquête. Le nourrisson et la mère ont obtenu un résultat positif au test de dépistage des anticorps antinucléaires et anti-Ro. L'électrocardiogramme, l'échocardiogramme, les analyses sanguines et les taux d'enzymes hépatiques du bébé étaient normaux. Nous avons diagnostiqué un lupus érythémateux cutané néonatal, recommandé une photoprotection et prescrit un onguent à base de tacrolimus à une concentration de $0,03 \%$, appliqué 2 fois par jour pour une période de 3 mois. À 12 mois, les lésions cutanées du patient s'étaient résorbées et les anticorps n'étaient plus présents. La mère n'a montré aucun symptôme de maladie auto-immune, mais les prochaines grossesses seront étroitement surveillées.

Le lupus érythémateux néonatal est un trouble peu fréquent causé par le transfert passif d'anticorps anti-Ro, anti-La ou antiribonucléoprotéine de la mère au bébé ${ }^{1}$. Il se caractérise par la manifestation de symptômes dermatologiques typiques, un bloc auriculoventriculaire congénital et un fibroélastose endocardique. Les nourrissons qui en sont atteints peuvent aussi présenter une maladie hépatobiliaire, une cytopénie, une macrocéphalie ou une hydrocéphalie ${ }^{2}$. Des symptômes s'apparentant au vitiligo ont aussi été décrits chez des nourrissons à la peau foncée ${ }^{3}$. Les manifestations de vitiligo au cours de la période néonatale 
sont exceptionnelles et devraient inciter les cliniciens à poursuivre leur investigation. Un suivi cardiaque devrait être accordé aux femmes qui ont donné naissance à un enfant atteint de lupus érythémateux néonatal cardiaque ou cutané, ainsi qu'à leur fœtus, lors de futures grossesses puisque le risque d'avoir un enfant atteint de lupus érythémateux néonatal cardiaque augmente de $20 \%$.

\section{Références}

1. Vanoni F, Lava SAG, Fossali EF, et al. Neonatal lupus erythematosus syndrome: a comprehensive review. Clin Rev Allergy Immunol 2017;53:469-76.

2. Boros CA, Spence D, Blaser S, et al. Hydrocephalus and macrocephaly: new manifestations of neonatal lupus erythematosus. Arthritis Rheum 2007;57: 261-6.

3. Jenkins RE, Kurwa AR, Atherton DJ, et al. Neonatal lupus erythematosus. Clin Exp Dermatol 1994;19:409-11.

Intérêts concurrents : Jérôme Coulombe signale avoir reçu des honoraires personnels de Galderma, Leo Pharma, Novartis et Pfizer, indépendamment des travaux soumis. Aucun autre intérêt concurrent n'a été déclaré.

Cet article a été révisé par des pairs.

Les auteurs ont obtenu le consentement parental.

Affiliations : Dermatologie (Coulombe) et rhumatologie (Barsalou), Service de pédiatrie, CHU Sainte-Justine, Université de Montréal, Montréal, Qc.

Propriété intellectuelle du contenu : Il s'agit d'un article en libre accès distribué conformément aux modalités de la licence Creative Commons Attribution (CC BY-NC-ND 4.0), qui permet l'utilisation, la diffusion et la reproduction de tout médium à la condition que la publication originale soit adéquatement citée, que l'utilisation se fasse à des fins non commerciales (c.-à-d., recherche ou éducation) et qu'aucune modification ni adaptation n'y soit apportée. Voir : https://creativecommons.org/licenses/by-nc-nd/4.0/deed.fr.

Correspondance : Jérôme Coulombe, jerome.coulombe@umontreal.ca 